\section{Attitudes and practices of dentists with respect to nutrition and periodontal health}

\author{
S. A. M. Kelly ${ }^{1}$ and P. J. Moynihan ${ }^{2}$
}

IN BRIEF

- Highlights the uncertainty among dentists about the current state of evidence for a therapeutic role of diet and nutrition in periodontal diseases.

- Summarises the current state of the evidence for the relationship between nutrition and periodontal health.

- There is a need for clinical guidance on what nutritional advice should be offered to patients.

\begin{abstract}
Objective To determine the opinions and attitudes of general dental practitioners and hygienists towards the role of nutrition in periodontal health. Setting The study was completed by general dental practitioners and dental hygienists throughout the UK. Method A questionnaire was sent out with the British Dental Journal and BDA News together with explanatory information about the study. Postage was pre-paid for replies. Results Eight hundred and seventy-nine questionnaires were completed. Sixty-six percent of respondents believed nutrition plays a role in periodontal health. Dietary factors that were considered most important were vitamin C (70\%), fruit and vegetables (64\%) and antioxidant vitamins (45\%). Forty-four percent had recommended nutrition supplements to their patients, with multivitamin and mineral supplements (37\%) and vitamin C (30\%) the most popular. Eighty-two percent of respondents sourced information from dental journals. Qualitative data highlighted uncertainty amongst respondents about the evidence base around nutrition and periodontal health and a lack of training opportunities. Conclusions A majority of dentists consider that nutrition and dietary factors play a role in maintaining periodontal health. However, there was a need to increase awareness of the current state of the evidence for a role of nutrition in maintaining periodontal health. Concern regarding lack of an evidence base for the role of nutrition in the treatment of periodontal diseases suggests a need for further research into the therapeutic role of nutrition in periodontal disease management.
\end{abstract}

\section{INTRODUCTION}

Improved understanding of the mechanisms of destruction of periodontal tissues and the potential protective role of nutrients and antioxidants have led to increased interest in the association between nutrition and periodontal health. ${ }^{1-4}$

Most recent data from the UK and Ireland suggest that the prevalence of chronic adult periodontitis remains high. The 1998 Adult Dental Health Survey in the UK found that 54\% of dentate adults had some periodontal pocketing of $4 \mathrm{~mm}$ or more and 5\% had deep pocketing of $6 \mathrm{~mm}$ or more, while $43 \%$ had some loss of attachment of $4 \mathrm{~mm}$ or more and $8 \%$

\footnotetext{
Research Associate, ${ }^{2}$ Reader in Nutrition and Oral Health, School of Dental Sciences, Newcastle University, Framlington Place, Newcastle-upon-Tyne, NE2 4BW ${ }^{*}$ Correspondence to: Dr Sarah Kelly Email:s.a.m.kelly@ncl.ac.uk
}

\section{Online article number E9}

Refereed Paper - accepted 23 April 2008

DOI: 10.1038/sj.bdj.2008.655

${ }^{\circledR}$ British Dental Journal 2008; 205: E9 had loss of attachment of $6 \mathrm{~mm}$ or more. ${ }^{5}$ The recent Irish Dental Survey based on data collected between 2000 and 2002 also reported a high level of periodontal disease and attachment loss in the population. In the over 65 age group, 38\% had periodontal pocketing of $4 \mathrm{~mm}$ or more and $12 \%$ had deep pocketing of $6 \mathrm{~mm}$ or more. Seventy-five percent had some loss of attachment of $4 \mathrm{~mm}$ or more and 36\% had loss of attachment of $6 \mathrm{~mm}$ or more. ${ }^{6}$

With the trend towards retention of teeth into old age as tooth loss through dental caries reduces, it is likely that the burden of adult periodontitis will increase.

While there are established functions for many nutrients in mechanisms for maintenance of the periodontal tissues, the evidence for a therapeutic role of nutrition in periodontal health is less clear. ${ }^{1-3,7}$ It is well documented that many other chronic health conditions such as obesity, diabetes and cardiovascular disease can be prevented by a healthier diet. ${ }^{8}$ There is also an increasing awareness of the links between general health and oral health. ${ }^{9}$ Periodontal disease has been linked with other health conditions which are known to be related to nutrition. In three separate analyses of the US Third National Health and Nutrition Examination Survey (NHANES III), statistically significant associations were found between periodontitis and body mass index, waist-to-hip ratio and fat-free mass in adults, ${ }^{10}$ a significant association was found between body mass index and waist circumference and periodontal disease in younger adults, ${ }^{11}$ and in an analysis of adolescents only, total body weight and waist circumference were associated with periodontitis in older adolescents aged 17 to 21 years. ${ }^{12}$ This suggests that being overweight or obese may be a risk factor for periodontitis and that dietary modification to reduce overweight and obesity might also have benefits for periodontal health.

Periodontitis has also been linked with type 2 diabetes (DM), cerebrovascular disease (CVD) and ischemic stroke. ${ }^{13-15}$ Consumption of a diet high in saturated 
fat and free sugars and low in fruits, vegetables and fibre may be the common risk factor that contributes to all of these diseases. ${ }^{8}$ There is strong evidence that consumption of a healthier diet prevents CVD, DM and obesity and may therefore directly, or indirectly though systemic disease prevention, prevent chronic adult periodontitis. ${ }^{8}$

Recent observational studies have demonstrated associations between dietary and nutritional components and periodontal diseases. In a prospective, observational study followed over 14 years, men in the highest quintile of wholegrain intake were 23\% less likely to get periodontitis than those in the lowest quintile. ${ }^{16}$ Further evidence of an association is available from cross-sectional studies. Both serum levels of vitamin $\mathrm{C}$ and dietary intake of vitamin $\mathrm{C}$ have shown a weak but statistically significant relationship to periodontal disease. ${ }^{17,18}$ An inverse association has been found between the intake of dairy products and prevalence of periodontitis. Those in the highest quintile of intake of dairy products were $20 \%$ less likely to have periodontitis than those in the lowest quintile after adjustment for periodontitis risk factors. ${ }^{19}$ An inverse association between calcium intake and prevalence of periodontitis has also been reported. ${ }^{20}$ Magnesium deficiency has also been reported to be associated with periodontal disease. Increased serum magnesium to calcium ratio has been linked with lower levels of attachment loss. ${ }^{21}$

There are, however, few intervention studies on the impact of changing diet on the progression of periodontal disease. A small randomised, double-blind study has shown that vitamin B complex can improve measures of periodontal wound healing. ${ }^{22}$ Supplementation with vitamin B complex led to significantly improved clinical attachment levels compared to placebo after access flap surgery. A nonrandomised trial has shown that grapefruit consumption increased plasma vitamin $\mathrm{C}$ levels and reduced sulcus bleeding index after two weeks. ${ }^{23}$

Moreover, the degree to which dentists consider nutrition to be important as part of total patient care with respect to periodontal disease is unknown. Neither is it known what dentists currently

\section{Table 1 Number of years since qualification of respondents}

\begin{tabular}{l|l}
\hline Number of years since qualification & Number $(\%)$ of respondents \\
\hline $0-5$ years & $121(13.8 \%)$ \\
\hline $5-10$ years & $108(12.3 \%)$ \\
\hline $10-15$ years & $77(8.6 \%)$ \\
\hline $15-20$ years & $127(14.5 \%)$ \\
\hline $20-30$ years & $272(30.9 \%)$ \\
\hline $30+$ years & $165(18.8 \%)$ \\
\hline Not answered & $9(1.0 \%)$ \\
\hline
\end{tabular}

\section{Table 2 Attitudes to the role of nutrition in periodontal health}

\begin{tabular}{|c|c|c|}
\hline Question & $\begin{array}{l}\text { Number of } \\
\text { respondents }\end{array}$ & $\begin{array}{l}\text { Percentage } \\
\text { of total } \\
\text { respondents } \\
(n=879)\end{array}$ \\
\hline $\begin{array}{l}\text { Do you believe that nutrition plays an important role in } \\
\text { the development of periodontal health? }\end{array}$ & 866 & \\
\hline Yes & 583 & 66.3 \\
\hline No & 70 & 8.0 \\
\hline Not sure & 213 & 24.2 \\
\hline $\begin{array}{l}\text { If yes, which of the following do you think is associated } \\
\text { with maintaining periodontal health (circle as many as apply)? }\end{array}$ & 693 & \\
\hline Vitamin C & 617 & 70.2 \\
\hline Antioxidant vitamins & 399 & 45.4 \\
\hline Flavonoids & 152 & 17.3 \\
\hline Berries & 245 & 27.9 \\
\hline Fruit and vegetables & 565 & 64.3 \\
\hline Other (please specify) & 167 & 19.0 \\
\hline $\begin{array}{l}\text { Do you or a colleague talk to patients about the role of nutrition } \\
\text { and eating a healthy diet in the development of periodontal health? }\end{array}$ & 807 & \\
\hline As a key component of regular patient care & 127 & 14.4 \\
\hline In response to a request for dietary advice & 71 & 8.1 \\
\hline When the situation suggests that this is required & 436 & 49.6 \\
\hline Never & 173 & 19.7 \\
\hline $\begin{array}{l}\text { Where do you source your information on nutrition } \\
\text { and periodontal health (please circle as many as apply)? }\end{array}$ & 826 & \\
\hline Dental journals & 725 & 82.5 \\
\hline Dietitian & 36 & 4.1 \\
\hline Nutritionist & 67 & 7.6 \\
\hline Other health professional (please specify) & 61 & 6.9 \\
\hline Food Standards Agency & 27 & 3.1 \\
\hline Personal knowledge and references & 401 & 45.6 \\
\hline Continuing professional development courses & 453 & 51.5 \\
\hline Other (please specify) & 72 & 8.2 \\
\hline
\end{tabular}


recommend to patients with or at risk of periodontal disease, with respect to diet. The aims of this study were therefore: (1) to investigate the views of dentists throughout the UK on nutrition as a risk factor for periodontal disease and (2) to obtain information on current practice with respect to nutrition advice for patients with periodontal disease.

\section{MATERIALS AND METHODS}

The survey questionnaire was designed based on existing knowledge of diet, nutrition and periodontal disease. The questionnaire consisted of open and closed structured questions on diet, nutrition, nutrition supplements and periodontal health. It also included a free text response section at the end of the questionnaire where respondents were invited to add any further comments. The questionnaire was included in three separate mailings of the British Dental Journal (23 June 2007) and BDA News (2 June, 7 July 2007) which are supplied to all dentists registered with the British Dental Association. Readers were invited to complete the survey and postage was pre-paid for all replies. All replies to the questionnaire received by 11 August 2007 were included in the analysis. A copy of the questionnaire is available from the authors on request.

Newcastle University School of Dental Sciences collated and analysed the data received from completed questionnaires. Numerical data were entered into an Excel spreadsheet and then analysed using SPSS (version 14). Thematic analysis on qualitative data written as free text was conducted by entering and coding the data using NVivo (QSR software, version 2). Thematic analysis is a method for identifying and analysing themes within data. ${ }^{24}$ Themes were chosen if they were raised by a large number of individual respondents so as to reflect issues of most importance to dentists and hygienists.

\section{RESULTS}

\section{General information}

A total of 879 replies were received, equivalent to $4.4 \%$ of all dentists registered with the British Dental Association. Eight hundred and forty-one (95.7\%) were dentists and 19 (2.2\%) were dental hygienists; 11 respondents (1.2\%) classified themselves as other occupations or specialities. Table 1 shows a breakdown of the respondents by number of years since qualification. Almost half of the respondents have been qualified for 20 years or more.

\section{General attitudes to nutrition and periodontal disease}

Sixty-six percent of dentists responded that they believe that nutrition plays an important role in the maintenance of periodontal health. Eight percent did not believe nutrition plays a major role and 24\% were not sure (Table 2).

Vitamin C (70\%), fruit and vegetables (64\%) and antioxidant vitamins (45\%) (Table 2) were most often chosen as factors associated with maintaining periodontal health. Nineteen percent listed 'Other'. In this section, there was an option for respondents to specify in writing other nutrition-related factors they considered important in maintaining nutritional health. The most commonly occurring themes were a good general balanced diet, co-enzyme Q10, B-vitamins and iron.

Fourteen percent of respondents indicated that they or a colleague talk to patients about the role of nutrition and eating a healthy diet in the maintenance of periodontal health 'as a key component of regular patient care' and 50\% 'when the situation suggests that this is required' (Table 2). A number of respondents commented in this section that they provide dietary advice for prevention of caries but not for periodontal health.

Eighty-two percent of respondents source their information about nutrition and periodontal health from dental journals (Table 2). From the free text data entered in this section, the Internet, newspapers, magazines or the media and books were also occasionally cited.

When asked about their perception of the percentage of patients visiting their surgery that exhibit symptoms of gum or other periodontal disease, respondents reported a mean of $67 \%(n=878$, SD 24) with some symptoms and of these, 22\% ( $n=879$, SD 14) were considered to be 'serious' and 10\% ( $\mathrm{n}=879$, SD 10) 'very serious'. Respondents considered that a mean of 29\% ( $n=791$, SD 26) of patients would see a benefit to their periodontal health from an improvement in diet.

\section{Attitudes to nutritional supplements}

In relation to periodontal health, 44\% of respondents have recommended to their patients that they take a nutritional supplement. Of these, approximately 7\% do so 'frequently' and 38\% do so 'sometimes' (Table 3).

Thirty-seven percent of respondents indicated they had recommended multivitamin and mineral supplements, 30\% vitamin C and 7\% calcium supplements

\begin{tabular}{|c|c|c|}
\hline Question & $\begin{array}{l}\text { Number of } \\
\text { respondents }\end{array}$ & $\begin{array}{l}\text { Percentage } \\
\text { of total } \\
\text { respondents } \\
(n=879)\end{array}$ \\
\hline $\begin{array}{l}\text { Do you recommend to your patients that they take nutritional } \\
\text { supplements to support or improve their periodontal health? }\end{array}$ & 876 & \\
\hline Frequently & 57 & 6.5 \\
\hline Sometimes & 333 & 37.9 \\
\hline Never & 486 & 55.3 \\
\hline $\begin{array}{l}\text { Have you recommended any of the following nutrition } \\
\text { supplements to your patients? }\end{array}$ & 489 & \\
\hline Calcium supplements & 65 & 7.4 \\
\hline Multivitamin and mineral supplements & 330 & 37.5 \\
\hline Vitamin C & 262 & 29.8 \\
\hline Other (please specify) & 171 & 19.5 \\
\hline
\end{tabular}


(Table 3). From free text data, other items recommended most frequently include co-enzyme Q10, B-vitamins, iron, fruit and vegetables and zinc.

\section{Themes from qualitative data entered as free text}

The strongest themes from the data were around uncertainty and lack of awareness about the evidence base for nutrition and periodontal health and about the need for training in nutrition and periodontal health.

Many respondents commented that the relationship between nutrition and periodontal disease is not often taught at dental schools and that there are few postgraduate or CPD courses:

'Not something that was ever even mentioned at dental school, consequently I have no knowledge on the subject and would not feel confident discussing the subject with patients.'

'Have never seen an advertised CPD course on this subject. Would be keen to learn more.'

Respondents also commented about lack of awareness of the evidence base for nutrition and periodontal health. Many were generally unsure whether there is a scientifically proven link between periodontal disease and nutrition:

'I was not aware of many refereed articles showing a relationship between periodontal disease and diet. Only article I read was in $\mathrm{BDJ}$ about a perio lecture in $B D A$ conference this year.'

'There is not much evidence for the role of nutrition in periodontal diseases - certainly not much is published in general or perio journals.'

'I am very interested in the subject but feel I don't have the evidence and knowledge to start giving nutritional advice.'

Many dentists commented about the need for evidence-based guidance for general dental practitioners about nutrition and periodontal disease and would like accessible evidence-based information to give to patients:

'I would appreciate an update on the advice to give to patients about the role of nutrition in periodontal health and also some evidence-based research results.'

'I would be really keen to see guidelines issued on a link between perio disease and nutrition. At the moment it is a bit like guesswork. A lot of [patients] attending with perio disease also have other health issues which could be linked to diet.'

While most dentists acknowledged a link between nutrition and periodontal health, there was also a strong theme that dentists consider other factors are more important to periodontal disease than nutrition. The factors repeatedly mentioned were oral hygiene in particular, smoking and genetic predisposition. Also occasionally mentioned were alcohol and sugar consumption frequency:

'I appreciate that there is a link but when you consider the vast majority see a compounding link with poor oral hygiene and smoking. Diet counselling has to come a poor third until the other two factors are addressed.'

'Periodontal health is influenced much more by smoking/plaque than nutrition, although $I$ do believe it plays a minor part.'

Some dentists commented that the current NHS contract allows inadequate time to provide nutritional advice to patients:

'The new target driven contract decreases the opportunity to spend time with patients and provide adequate preventative advice.'

'Would like NHS to be less pressurised (UDAs) so as to have time to address such issues as diet, nutrition and perio state.'

\section{DISCUSSION}

This study provides a useful insight into the views and practices of dental practitioners in the UK in relation to nutrition and periodontal health and is based on real experience in general practice. Few studies have collected data on the provision of nutritional advice in general dental practice and none in relation to periodontal disease. This survey was circulated to the readership of the $B D J$ and $B D A$ News. It is possible that those dentists and hygienists most inter- ested in nutrition are most likely to have responded. However, from analysis of the questionnaires, it is clear that replies were received from those with both positive and negative attitudes to nutrition. Although being open to the entire readership, the majority of respondents were dentists, with only just over $2 \%$ being hygienists, therefore no sub-analysis according to profession was conducted.

The majority of respondents believed that nutrition plays a role in periodontal health. However, the first area of concern highlighted by the responses to this survey is that there is uncertainty among dentists about what the evidence base is for a therapeutic role for nutrition in the treatment of periodontitis.

Most of the studies that have been conducted in this area are observational studies which suggest that there may be a relationship between certain aspects of diet and periodontal disease, including an inverse association with intake of vitamin C, calcium and wholegrains. ${ }^{16-18,20,21}$ Furthermore, there is a well established link between consumption of a healthier diet and prevention of many chronic diseases associated with periodontitis. ${ }^{8}$ Despite this, there is a lack of dietary intervention studies in the form of randomised controlled trials in this area to demonstrate whether nutrition has a therapeutic effect in the management of periodontal disease. There is a need for more clinical trials to clarify and strengthen the evidence base in this area.

The World Health Organization (WHO) has used defined criteria to assess the strength of the evidence between dietary components and health in its report on Diet, nutrition and the prevention of chronic diseases. ${ }^{8}$ Evidence was categorised into levels based on available information. The levels were "convincing evidence', 'probable evidence', 'possible evidence' and 'insufficient evidence'. Using the WHO criteria, the current situation would support a grade of "possible evidence' for a relationship between diet and nutrition in the prevention of periodontal disease. The evidence is based mainly on findings from cross-sectional studies. Few longitudinal observational studies or randomised controlled trials are available. Data from the few intervention studies that have been conducted 
are supportive of a link and an association is also biologically plausible. ${ }^{1,2,7}$

The studies that are available have usually examined the effect of one nutritional or dietary component in isolation. It is likely, however, that many nutrients work together in promoting both general health and periodontal health ${ }^{3}$ and many respondents did comment on the importance of a well-balanced diet to overall health. A common risk factor approach has previously been proposed for the promotion of oral health. This approach takes into account that the causes of oral health conditions are multifactorial and likely to be common to other chronic diseases. ${ }^{9}$

Many of the dentists who responded to this survey commented that the area of nutrition and periodontal health is little taught in dental schools in the UK and there are few continuing professional development courses available. This is perhaps reflected in the finding that only $14 \%$ provided dietary advice as a regular part of patient care. Despite this, 44\% recommended some form of nutritional supplementation to their patients (Table $3)$. While recent graduates from dental schools do receive some nutritional education as part of their undergraduate training, ${ }^{25,26}$ these findings suggest there is a need for more training and for clinical guidelines on what nutrition advice to offer patients.

There was a belief among many respondents that the effect of nutrition may be minor compared to the overall influence of smoking, oral hygiene and genetic predisposition. Smoking and oral hygiene are undoubtedly major risk factors for periodontal disease with a strong evidence base. ${ }^{27}$ However, the therapeutic potential of improving diet and nutrition in patients with periodontitis has not been measured and randomised controlled trials in this area are needed. What is well established is that a diet low in saturated fat and free sugars and high in fruit, vegetables and fibre is protective against DM, CVD and obesity. If these conditions predispose to periodontal diseases, then systemic disease prevention through promoting a healthier diet will also benefit periodontal health.

\section{CONCLUSIONS}

There is concern amongst dentists that the level of evidence as it stands may not be strong enough to support a therapeutic role of diet and nutrition in periodontal diseases. However, this is largely due to an inadequate number of studies rather than negative findings. Welldesigned clinical trials of diet and nutrition intervention are needed to clarify the potential role of nutrition in the prevention and treatment of periodontal disease. This study has also highlighted a need for nutrition training in this area for both undergraduates and as part of continuing professional development.

This study was funded by Dentaplex UK Ltd, a subsidiary of Trinity Lifecare Ltd.

1. Chapple I L C, Matthews J B. The role of reactive oxygen and antioxidant species in periodontal tissue destruction. Periodontol 2000 2007: 43: 160-232.

2. Chapple I L C, Milward M R, Dietrich T. The prevalence of inflammatory periodontitis is negatively associated with serum antioxidant concentrations. J Nutr 2007; 137: 657-664.

3. Moynihan P. Update on nutrition and periodontal disease. Quintessence Int in press.

4. Boyd L D, Lampi K J. Importance of nutrition for optimum health of the periodontium. J Contemp Dent Pract 2001; 2(2): 36-45.

5. Kelly M, Steele J, Nuttall N et al. Adult dental health survey. Oral health in the United Kingdom 1998. London: The Stationery Office, 2000.

6. Whelton $\mathrm{H}_{1}$ Crowley $\mathrm{E}, \mathrm{O}$ 'Mullane $\mathrm{D}$ et al. Oral health of Irish adults 2000-2002. Dublin: Department of Health and Children and Brunswick Press Ltd, 2007.

7. Enwonwu C O. Cellular and molecular effects of malnutrition and their relevance to periodontal disease. J Clin Periodontol 1994; 21: 643-657.

8. World Health Organization. Diet, nutrition and the prevention of chronic diseases. WHO Technical report series 916. Geneva: WHO/FAO, 2003.

9. Sheiham A, Watt R G. The common risk factor approach: a rational basis for promoting oral health. Community Dent Oral Epidemiol 2000; 28: 399-406.

10. Wood N, Johnson R B, Streckfus C F. Comparison of body composition and periodontal disease using nutritional assessment techniques: third national health and nutrition examination survey (NHANES III). J Clin Periodonto/ 2003; 30: 321-327.

11. Al-Zahrani M S, Bissada N F, Borawskit E A. Obesity and periodontal disease in young, middle-aged and older adults. J Periodonto/ 2003; 74: 610-615.

12. Reeves A F, Rees J M, Schiff M, Hujoel P. Total body weight and waist circumference associated with chronic periodontitis among adolescents in the United States. Arch Pediatr Adolesc Med 2006; 160: 894-899.

13. Mealey B L, Oates T W. Diabetes mellitus and periodontal diseases. J Periodontol 2006; 77: 1289-1303.

14. Wu T, Trevisan M, Genco R J, Dorn J P, Falkner K L, Sempos C T. Periodontal disease and risk of cerebrovascular disease: the first national health and nutrition examination survey and its follow-up study. Arch Intern Med 2000; 160: 2749-2755.

15. Joshipura K J, Hung H-C, Rimm E B, Willett W C, Ascherio A. Periodontal disease, tooth loss, and incidence of ischemic stroke. Stroke 2003; 34: 47-52.

16. Merchant A T, Pitiphat W, Franz M, Joshipura K J. Whole-grain and fiber intakes and periodontitis risk in men. Am J Clin Nutr 2006; 83: 1395-1400.

17. Amarasena N, Ogawa H, Yoshihara A, Hanada N, Miyazaki H. Serum vitamin $\mathrm{C}$-periodontal relationship in community-dwelling elderly Japanese. J Clin Periodontol 2005; 32: 93-97.

18. Nishida M, Grossi S G, Dunford R G, Ho A W, Trevisan M, Genco R J. Dietary vitamin C and the risk for periodontal disease. J Periodontol 2000; 71: 1215-1223.

19. Al-Zahrani M S. Increased intake of dairy products is related to lower periodontitis prevalence. J Periodonto/ 2006; 77: 289-294.

20. Nishida M, Grossi S G, Dunford R G, Ho A W, Trevisan M, Genco R J. Calcium and the risk for periodontal disease. J Periodontol 2000; 71: 1057-1066.

21. Meisel P, Schwahn C, Luedemann J, John U, Kroemer H K, Kocher T. Magnesium deficiency is associated with periodontal disease. J Dent Res 2005; 84: 937-941.

22. Neiva R F, Al-Shammari $K$, Nociti F H, Jr., Soehren $\mathrm{S}$, Wang $\mathrm{H}$-L. Effects of vitamin-B complex supplementation on periodontal wound healing. J Periodontol 2005; 76: 1084-1091.

23. Staudte H, Sigusch B W, Glockmann E. Grapefruit consumption improves vitamin $C$ status in periodontitis patients. Br Dent J 2005; 199: 213-217.

24. Miles M, Hurberman M. Qualitative data analysis: an expanded sourcebook. London/Thousand Oaks, CA: Sage Publications, 1994.

25. General Dental Council. The first five years a framework for undergraduate dental education. 1st ed. London: General Dental Council, 1997.

26. General Dental Council. The first five years - a framework for undergraduate dental education. 2nd ed. London: General Dental Council, 2002.

27. Burt B, Greenwell H, Fiorellini J et al. Epidemiology of periodontal diseases. J Periodontol 2005; 76: 1406-1419. 